\title{
Work pressure, emotional demands and work performance among information technology professionals in South Africa: The role of exhaustion and depersonalisation
}

\begin{tabular}{|c|c|}
\hline \multicolumn{2}{|c|}{$\begin{array}{l}\text { Authors: } \\
\text { Jessica Dos Santos } \text { Tome }^{1} \\
\text { Leoni van der Vaart }^{1}\end{array}$} \\
\hline \multicolumn{2}{|c|}{$\begin{array}{l}\text { Affiliations: } \\
{ }^{1} \text { School of Industrial } \\
\text { Psychology and Human } \\
\text { Resource Management, } \\
\text { North-West University, } \\
\text { Potchefstroom, South Africa }\end{array}$} \\
\hline \multicolumn{2}{|c|}{$\begin{array}{l}\text { Corresponding author: } \\
\text { Leoni van der Vaart, } \\
\text { 12772356@g.nwu.ac.za }\end{array}$} \\
\hline \multicolumn{2}{|c|}{$\begin{array}{l}\text { Dates: } \\
\text { Received: } 21 \text { Mar. } 2020 \\
\text { Accepted: } 06 \text { Aug. } 2020 \\
\text { Published: } 08 \text { Oct. } 2020\end{array}$} \\
\hline \multicolumn{2}{|c|}{$\begin{array}{l}\text { How to cite this article: } \\
\text { Dos Santos Tome, J., \& Van der } \\
\text { Vaart, L. (2020). Work } \\
\text { pressure, emotional demands } \\
\text { and work performance among } \\
\text { information technology } \\
\text { professionals in South Africa: } \\
\text { The role of exhaustion and } \\
\text { depersonalisation. SA Journal } \\
\text { of Human Resource } \\
\text { Management/SA Tydskrif vir } \\
\text { Menslikehulpbronbestuur, } \\
\text { 18(0), a1362. https://doi. } \\
\text { org/10.4102/sajhrm. } \\
\text { v18i0.1362 }\end{array}$} \\
\hline \multicolumn{2}{|c|}{$\begin{array}{l}\text { Copyright: } \\
\text { (c) 2020. The Authors. } \\
\text { Licensee: AOSIS. This } \\
\text { is licensed under the } \\
\text { Creative Commons } \\
\text { Attribution License. }\end{array}$} \\
\hline \multicolumn{2}{|l|}{ Read online: } \\
\hline 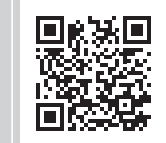 & $\begin{array}{l}\text { Scan this QR } \\
\text { code with your } \\
\text { smart phone or } \\
\text { mobile device } \\
\text { to read online. }\end{array}$ \\
\hline
\end{tabular}

Orientation: Technological advancements are occurring at a rapid rate, and individuals working in information technology (IT) often work under challenging and emotionally demanding circumstances. Also, there is a shortage of IT professionals, and organisations have difficulty retaining them. These circumstances may result in exhaustion and depersonalisation that have negative consequences for the work performance of the remaining IT professionals.

Research purpose: This research aimed to investigate the relationships between work pressure, emotional demands, exhaustion, depersonalisation, task performance and counterproductive work behaviour among IT professionals within South Africa.

Motivation for the study: Research on the individual work performance of IT professionals, specifically in South Africa, is limited in number and scope.

Research approach/design and method: In this study, a quantitative approach was used to collect cross-sectional data from a convenience sample of 296 IT professionals in South Africa.

Main findings: Results from structural equation modelling (SEM) indicated that emotional demands and depersonalisation impacted task performance positively and negatively, respectively. Depersonalisation positively impacted counterproductive work behaviour, and work pressure positively impacted exhaustion.

Practical/managerial implications: Organisations should aim to create awareness of IT professionals experiencing emotional demands, work pressure and depersonalisation as there are consequences for these behaviours. Beyond awareness creation, management should design and implement interventions to optimise emotional demands and to minimise work pressure and depersonalisation.

Contribution/value-add: The study contributes to the limited literature on IT professionals' work performance within a South African context by providing insights on the role exhaustion and depersonalisation play (or the lack thereof) in explaining the effect of work demands on individual work performance.

Keywords: job demands; task performance; counterproductive work behaviour; indirect effects; IT professionals; South Africa.

\section{Introduction}

The Fourth Industrial Revolution (4th IR) - a digital revolution occurring at an exponential rate - has a significant impact on organisations (Marr, 2018; Schwab, 2016). Although this digital revolution presents opportunities (e.g. connecting people and optimising organisational efficiency) (Schwab, 2016), most organisations struggle to keep up with the technological advancements (Holly, 2018). Organisational success, in this digital era, is highly dependent on information technology (IT) professionals who can bridge the gap between technological potential and the practical reality thereof (Murphy, 2018). Consequently, there is significant pressure on IT professionals to perform (Anderson \& Rainie, 2018). However, these professionals have added burdens created by a global shortage of IT skills (Brooks, Greer, \& Morris, 2018; Naidoo, 2018) and high turnover rates among these professionals (Diedericks \& Rothmann, 2014; Van Zyl, Van Oort, Rispens, \& Olckers, 2019). 
Doing more with less (i.e. high workload) has implications for performance (Van Zyl et al., 2019), but it is only one side of the coin. In delivering services, IT professionals often encounter clients that are demanding and/or unhappy (Nexus Group, 2018). Increased workloads coupled with emotionally laden encounters potentially hamper performance (Plaatjies \& Mitrovic, 2014) to such an extent that it may also lead to negative (or counterproductive) work behaviours (Ceschi, Sartori, Dickert, \& Costantini, 2016; Chen, Li, Xia, \& He, 2017). These consequences are often not only as a direct result of work-related demands but also because employees suffer psychologically; they are emotionally exhausted and detached from their work (Schaufeli, 2017).

Although evidence exists that supports the belief that employees' job demands have an impact on their well-being, which in turn influence their performance (Schaufeli, 2017; Tomo \& De Simone, 2018), these studies rarely focus explicitly on IT professionals (Zakaria, Abdulatiff, \& Ali, 2014; Zakariah, Zainal, \& Shariff, 2018). Within the South African context, studies focussing on IT professionals (or more broadly, employees in the IT industry) mainly investigated flexible work arrangements (Conradie \& De Klerk, 2019), retention (Naidoo, 2018; Van Dyk \& Coetzee, 2012) or wellbeing (Diedericks \& Rothmann, 2014). Naidoo (2018) included job performance but neglected to focus on negative performance behaviours.

This is unfortunate because (1) performance of IT professionals is relevant in the current world of work, and (2) it cannot be assumed that all demands are equal in terms of their impact on, for example, performance (Li, Taris, \& Peeters, 2019; Van den Broeck, De Cuyper, De Witte, \& Vansteenkiste, 2010). Therefore, results cannot be haphazardly extrapolated from one context to the next.

To address the limitations identified in literature, the current study investigated the relationship between the job demands (i.e. work pressure and emotional demands) and performance of IT professionals in the South African context. More specifically, this study investigated the direct and indirect role of job demands in influencing performance through illbeing (i.e. exhaustion and depersonalisation). In doing so, this study contributes to individual work performance literature from an IT professional's perspective. The practical value-add of the study lies in organisations (and individuals) benefiting from an understanding of the impact of the work environment on IT professionals' well-being and individual work performance. Stakeholders can use this understanding to design and implement evidence-based interventions to optimise well-being and performance and, ultimately, organisational success.

\section{Literature review}

\section{Work pressure and emotional demands}

Work pressure relates to the amount of work, the amount of time taken to complete and how often an employee is stretched to meet deadlines (Ahuja \& Rathore, 2018;
Bakker, 2014). Because of the nature of their work, IT professionals are faced with high levels of work pressure. Not only does the current technologically orientated environment demand a lot, but they must also often work overtime upgrading and maintaining software, ensuring office computer networks are functioning, and maintaining databases (Deal, 2013; Koong, Liu, \& Lui, 2015). These are tasks that one can often not postpone. Information technology professionals also provide client services such as designing, managing, supporting or implementing systems or products (Naidoo, 2018). Information technology professionals may not have an emotional attachment to their job content as they simply regard performing tasks as part of their job. However, they may experience emotionally demanding situations when dealing with client complaints and dissatisfaction (Rutkowski \& Saunders, 2018). In these situations, IT professionals may be required to continually invest emotional effort (Rutkowski \& Saunders, 2018) to regulate their own or others' feelings (Vammen, 2016). Such situations can include emotionally loaded encounters with demanding clients, or even disrespect and rudeness (Bakker, 2014), leading to increased emotional demands.

\section{Exhaustion and depersonalisation}

Burnout is often used in organisational psychology literature as an indicator of employee ill-being (De Beer \& Bianchi, 2019; Maslach \& Leiter, 2016). It is a psychological syndrome that develops as a result of prolonged exposure to demands at work (Maslach \& Leiter, 2016). Emotional exhaustion - one dimension of burnout (Maslach \& Jackson, 1986) - is described as a chronic state of emotional depletion, loss of energy, debilitation and fatigue (Maslach \& Leiter, 2016). Emotional exhaustion occurs when IT employees feel emotionally drained and overwhelmed by the demands of their work (Cafasso, 2018). Depersonalisation - another dimension of burnout (Maslach \& Jackson, 1986) - can be referred to as a cynical or detached attitude towards others at work and serves as a protection mechanism against the psychological stress stemming from interactions with others (Maslach \& Leiter, 2016). Furthermore, depersonalisation can be described as presenting a sustained and composite negative response towards different working conditions (e.g. working hours), which can cause a skewed perspective of one's work (Barker, 2016). Although burnout is also characterised by reduced personal accomplishment (Maslach \& Jackson, 1986), this symptom was excluded from the current study. More and more studies show that exhaustion and cynicism constitute the core of burnout, and that reduced personal accomplishment should instead be modelled as an outcome of the syndrome (De Beer \& Bianchi, 2019).

\section{Individual work performance}

Individual work performance is defined as 'employee behaviours or actions that are relevant to the goals of the organization' (Campbell, 1990, p. 67). Task performance can be defined as 'proficiency with which central job tasks are performed' (Koopmans et al., 2011, p. 862). These proficient 
behaviours include behaviours that contribute directly to the technical core and maintenance activities in an organisation (Aguinis, 2013). Typical behaviours include completing job tasks, updating knowledge and planning and organising (Koopmans et al., 2011); these behaviours are all relevant in the IT context. Counterproductive behaviour at work is a serious concern because of its negative consequences for the organisation's reputation, stakeholders and/or ethical culture (Vorster, 2018). Counterproductive work behaviour (CWB) is any intentional, unacceptable or harmful behaviours that have the potential to have negative consequences for an organisation's operational and financial well-being and the staff members within that organisation. Typical behaviours include complaining and spreading unwanted messages about the organisation (Koopmans et al., 2011).

\section{The relations between work pressure and emotional demands, exhaustion and depersonalisation, and performance from job demands-resources perspective}

The current study is positioned within the job demandsresources (JD-R) theory (Demerouti, Bakker, Nachreiner, \& Schaufeli, 2001) and more specifically within the energetic process of the theory. The JD-R theory posits that every workplace has characteristics that can be categorised into job demands and job resources (Bakker \& Demerouti, 2014). Job demands have been described as those 'physical, social, and organizational aspects of the job that require sustained physical or mental effort and are therefore associated with certain physiological and psychological costs' (Demerouti et al., 2001, p. 501). In the current study, work pressure and emotional demands are positioned as job demands. The energetic process of the theory postulates that job demands, in general, are associated with costs and influence both wellbeing and performance negatively (Bakker \& Demerouti, 2014, 2017). A large body of evidence supports this (see Lesener, Gusy, \& Wolter, 2019; and Schaufeli \& Taris, 2014 for overviews).

Information technology professionals who are dealing with job demands, such as work pressure and emotional demands, report an inability to perform optimally (Plaatjies \& Mitrovic, 2014). Emotional demands were also found to have an impact on IT professionals' performance, as these professionals spend energy on managing their emotions in client interactions and support (Cafasso, 2018). In contrast, job demands have a positive relationship with CWB. This may be a consequence of feeling overwhelmed and/or reacting negatively to these demands (Ceschi et al., 2016; Chen et al., 2017). Consistent with theory and previous research, it is expected that there is a negative relationship between work pressure and task performance (Hypothesis 1a) but a positive relationship between work pressure and CWB (Hypothesis $1 b)$. It is also expected that there is a negative relationship between emotional demands and task performance (Hypothesis 2a) but a positive relationship between emotional demands and CWB (Hypothesis 2b).
After prolonged exposure to work pressure and emotional demands, employees may become chronically exhausted and distance themselves psychologically from their work (Bakker, Schaufeli, Sixma, Bosveld, \& Van Dierendonck, 2000). In other words, they may start experiencing burnout because of high job demands (De Beer \& Bianchi, 2019; Gauche, De Beer, \& Brink, 2017; Hsu, 2019). Consistent with theory and previous research, it is expected that there is a positive relationship between work pressure and exhaustion (Hypothesis 3a) and depersonalisation (Hypothesis 3b), respectively. It is also expected that there is a positive relationship between emotional demands and exhaustion (Hypothesis 4a) and depersonalisation (Hypothesis 4b), respectively.

Employers may also start noticing changes in employees' job performance because employees are overworked and emotionally exhausted (Bang \& Reio, 2017; Campbell, 2016). This could be because they feel less confident to solve work problems (Bakker, Demerouti, Taris, Schaufeli, \& Schreurs, 2003), they lack emotional and physical resources (Wallgren, 2013) or because they are attempting to conserve their energy (Tourigny, Vishwanath, Han, \& Wang, 2012). Employees may become so emotionally exhausted and detached from their tasks that they display CWBs (Studebaker, 2017). Burnout, or some of its symptoms, has been found to be positively associated with CWB (Bang, \& Reio, 2017; Bolton, Harvey, \& Grawitch, 2012; Ugwu, Enwereuzor, Fimber, \& Ugwu, 2017). Consistent with theory and previous research, it is expected that there is a negative relationship between exhaustion and task performance (Hypothesis $5 a$ ) but a positive relationship between exhaustion and CWB (Hypothesis 5b). It is also expected that there is a negative relationship between depersonalisation and task performance (Hypothesis $6 a$ ) but a positive relationship between depersonalisation and $\mathrm{CWB}$ (Hypothesis 6b).

\section{The indirect effect of work pressure and emotional demands on job performance}

As illustrated above, direct relationships may exist between job demands and performance, between job demands and illbeing and between ill-being and performance. However, indirect relationships between job demands and performance may also exist. It is necessary to investigate such indirect relationships because Lang, Thomas, Bliese and Adler (2007) explain that the demands-performance link is generally weak. The JD-R theory provides a useful framework for investigating the impact of job demands (i.e. determinants) on individual work performance (i.e. outcome) through exhaustion and depersonalisation (i.e. mediators) (Schaufeli \& Bakker, 2004). The theory explains that the increase in demands may result in burnout (exhaustion and depersonalisation), which in turn may lead to adverse performance outcomes for the individual (Schaufeli, 2017).

Daily job demands, such as having to work long hours and providing a service and support function in the IT environment, may not only exhaust IT professionals but may 
also lead to them detaching from work, which can lead to poor task performance and CWB. Empirical evidence supports this. For example, studies found that exhaustion partially mediated the relationship between demands and performance (Ceschi et al., 2016; Onwezen, Van Veldhoven, \& Biron, 2014). Depersonalisation also mediated the relationship between job demands and individuals' work performance (Kar \& Suar, 2014; Lee, Ok, Lee, \& Lee, 2018). Consistent with theory and previous research, it is expected that work pressure and emotional demands indirectly affect task performance through exhaustion (Hypothesis 7a) and depersonalisation (Hypothesis 7b). It is also expected that work pressure and emotional demands indirectly affect CWB through exhaustion (Hypothesis 8a) and depersonalisation (Hypothesis 8b).

\section{Research design Research approach}

A cross-sectional survey design was used to achieve the research objectives. This design translates into the collection of data at a single point in time. Cross-sectional designs are often used, as an essential first step, to determine whether variables are related before investing resources in longitudinal studies (Spector, 2019).

\section{Research method \\ Participants}

The participants were sampled from various South African organisations. A convenience sample of IT professionals across various organisations was included $(n=296)$. The sample consisted of both females (25.7\%) and males (74.3\%). The average age of the respondents was 37 years (standard deviation $[\mathrm{SD}]=9.81$ ). The average tenure in the same position was 6 years $(\mathrm{SD}=5.85)$.

\section{Measuring instruments}

A biographical questionnaire was used to determine age, gender and years of experience within the current position. Work pressure and emotional demands were measured by using the Demands-Resource Questionnaire (JDRQ) (Bakker, 2014). Participants were expected to rate these two demands by using a five-point frequency scale ranging from 1 (never) to 5 (very often). Work pressure had four items (e.g. 'Do you work under time pressure?'), and emotional demands comprised six items (e.g. 'Is your work emotionally demanding?').

Exhaustion and depersonalisation were measured by using the Maslach Burnout Inventory - General Survey (MBI) (Schaufeli, Leiter, Maslach, Jackson, \& Schwab, 1996). Participants were required to rate themselves on a scale ranging from 1 (never) to 5 (very often). Exhaustion (e.g. 'I feel emotionally drained from my work') and depersonalisation (e.g. 'I have become less enthusiastic about my work') were measured by using five items each.
Task performance and CWB were measured by using the Individual Work Performance Questionnaire (IWPQ 1.0) (Koopmans, 2015). Task performance consisted of five items (e.g. 'I kept in mind the results that I had to achieve in my work') measured on a five-point frequency scale ranging from 1 (seldom) to 5 (always). Counterproductive work behaviour also consisted of five items (e.g. 'I made problems greater than they were at work') measured on a five-point frequency scale ranging from 1 (never) to 5 (often).

\section{Procedure}

The relevant research ethics committee granted ethics approval prior to data collection. Convenience sampling was used to collect data via three avenues: door-to-door, social media and a research company. Door-to-door recruitment entailed meetings with gatekeepers to provide information regarding the research and to obtain permission to distribute the questionnaire among their employees. In all three instances, a mail was sent to prospective participants containing information about the study and a link to the consent form and the questionnaire.

\section{Statistical analysis}

For the purpose of this study, both IBM SPSS 25 (IBM Corporation, 2016) and Mplus version 8.2 (Muthén \& Muthén, 1998-2018) were used. To determine the validity of the instruments, and to identify the best fitting measurement model, confirmatory factor analyses (CFA) were performed. By means of structural equation modelling (SEM), a structural model was estimated by inserting the hypothesised regression paths based on the best fitting measurement model. The models were estimated by using the maximum likelihood robust (MLR) estimator, which is robust to skewness and kurtosis (Kline, 2016).

The indices that were used to interpret the measurement and structural models' fit to the data included the chi-square $\left(\chi^{2}\right)$, degrees of freedom $(d f)$, root mean square error of approximation (RMSEA), standardised root means square residual (SRMR) and incremental fit indices (i.e. TuckerLewis index [TLI] and the comparative fit index [CFI]). The CFI and TLI should yield values above 0.95 to be acceptable (Hu \& Bentler, 1999), but should be treated as guidelines in applied research (West, Taylor, \& Wu, 2012). Wang and Wang (2020) consider 0.90 as appropriate cut-off values for these two fit indices. Further, SRMR values closer to 0.08 indicate acceptable fit between the model and the data (Wang \& Wang, 2020). The RMSEA values should be less than 0.08 to indicate an acceptable fit (Kline, 2016). In addition to the incremental fit indices, comparative fit indices (Akaike information criterion [AIC] and the Bayes information criterion $[\mathrm{BIC}]$ ) were used to compare the different measurement and structural models. The model with the lowest value is preferred (Kline, 2016). Based on the bestfitting structural model, the potential indirect effects of work pressure and emotional demands on task performance and CWB through exhaustion and depersonalisation were tested. 
Bootstrapping and the construction of bias-corrected 95\% confidence intervals (CIs) were used to test the indirect effects (Hayes, 2017) of work pressure and emotional demands.

Effect sizes were utilised as indicators of practical significance for correlations with $\geq 0.30$ representing a medium effect and $\geq 0.50$ representing a large effect (Cohen, 1992). To evaluate the reliability of the measuring instruments, composite reliability coefficients $(\rho)$ were calculated with a cut-off point of 0.70 (Wang \& Wang, 2020). Composite reliability was used as it is more accurate than Cronbach's alpha coefficients when using latent variable modelling to determine the internal consistency of the constructs (Raykov, 2009). However, Cronbach's coefficient alpha is also reported for transparency and potential future research purposes.

\section{Ethical consideration}

Ethics approval was granted by the research ethics committee of the NWU (No. NWU-HS-2017-0046).

\section{Results}

\section{Testing measurement models}

Four competing measurement models were tested by using CFA because of the cross-sectional nature of the data. In Model 1, work pressure, emotional demands, exhaustion, depersonalisation, task performance and CWB were specified as six separate factors with items loading onto their respective a-priori factors. In Model 2, work pressure and emotional demands were specified as one factor (i.e. work demands), depersonalisation and exhaustion were specified as one factor (i.e. ill-being) and task performance and CWB were specified as two separate factors. In Model 3, work pressure and emotional demands were specified as one factor (i.e. work demands) with exhaustion, depersonalisation, task performance and CWB as four separate factors. In Model 4, work pressure and emotional demands were specified as two separate factors, depersonalisation and exhaustion were specified as one factor (i.e. burnout) and task performance and CWB were specified as two separate factors. Model fit statistics are reported in Table 1.

Based on the results and the recommended cut-off values, Model 1 fitted the data better than the competing models. Critique is leveraged against more complex models having a better fit (Kline, 2016) and Model 1 is the most complex of the four models. To address this critique, the AIC and BIC values are compared. Akaike information criterion and BIC penalise model complexity so that simpler theoretical models are favoured over more complex ones (Adams, 2018). Hence, in addition to the CFI, TLI and RMSEA values being closer to the cut-off values, the AIC and BIC values were also the lowest for Model 1. However, Model 1 only partially met the criteria and, consequently, the model needed to be improved.

\section{Model improvement}

To improve the model's fit, certain items were removed, and the error of variances of some items was correlated. Modification indices were used to guide model development, and the fit statistics for the revised models are reported in Table 2. In Model 1a problematic items were deleted: (a) work pressure items 1 ('Do you have to work at speed?'), 2 ('Do you have too much work to do?') and 3 ('How often do you have to work extra hard in order to reach a deadline?') and (b) depersonalisation item 3 ('I just want to do my job and not be bothered'). These items were problematic, as they crossloaded repeatedly on other constructs as opposed to their own theoretical constructs. Despite these modifications, the fit statistics of Model 1a did not meet the required cut-off

\begin{tabular}{|c|c|c|c|c|c|c|c|c|c|}
\hline Model & $\chi^{2}$ & $d f$ & $p$ & CFI & TLI & SRMR & $\begin{array}{c}\text { RMSEA } \\
{[90 \% \mathrm{Cl}]}\end{array}$ & AIC & BIC \\
\hline Model 1 & 966.03 & 390 & 0.00 & 0.85 & 0.83 & 0.07 & $\begin{array}{c}0.07^{*} \\
{[0.07,0.08]}\end{array}$ & 25657.13 & 26044.62 \\
\hline Model 2 & 1443.63 & 399 & 0.00 & 0.73 & 0.70 & 0.09 & $\begin{array}{c}0.09 * \\
{[0.09,0.10]}\end{array}$ & 26203.04 & 26557.32 \\
\hline Model 3 & 1130.86 & 395 & 0.00 & 0.81 & 0.79 & 0.08 & $\begin{array}{c}0.08^{*} \\
{[0.07,0.09]}\end{array}$ & 25842.29 & 26211. 32 \\
\hline
\end{tabular}

$\chi^{2}$, chi-square statistic; $d f$, degree of freedom; $p$, significance; CFI, comparative fit index; TLI, Tucker-Lewis index; SRMR, standardised root means square residual; RMSEA, root mean square error of approximation; $\mathrm{Cl}$, confidence interval; AIC, Akaike information criterion; BIC, Bayes information criterion.

$*, p<0.05$.

TABLE 2: Model fit statistics for model improvement.

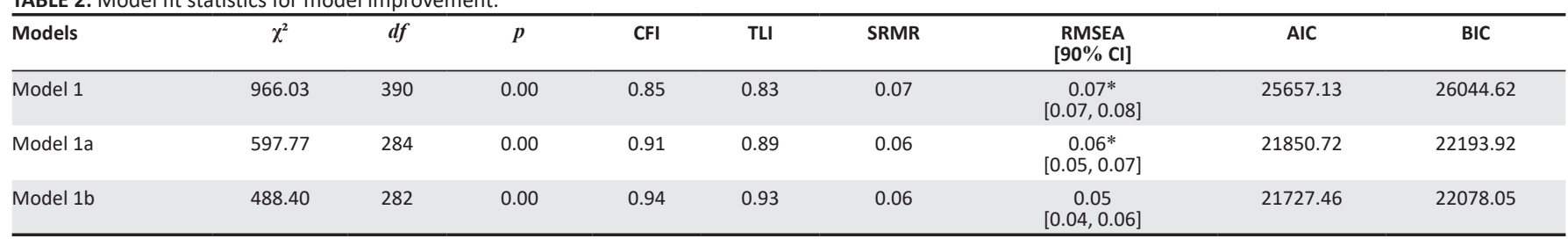

$\chi^{2}$, chi-square statistic; $d f$, degree of freedom; $p$, significance; CFI, comparative fit index; TLI, Tucker-Lewis index; SRMR, standardised root means square residual; RMSEA, root mean square error of approximation; $\mathrm{Cl}$, confidence interval; AIC, Akaike information criterion; BIC, Bayes information criterion.

$*, p<0.05$. 
TABLE 3: Correlation matrix including reliabilities means and standard deviations.

\begin{tabular}{|c|c|c|c|c|c|c|c|c|c|}
\hline Variable & $M$ & SD & $\alpha$ & $P$ & 1 & 2 & 3 & 4 & 5 \\
\hline Work pressure & 3.57 & 0.88 & 0.83 & 0.83 & - & - & - & - & - \\
\hline Emotional demands & 2.84 & 1.07 & 0.84 & 0.84 & $0.39 * *$ & - & - & - & - \\
\hline Exhaustion & 2.68 & 1.57 & 0.91 & 0.91 & $0.47 * *$ & $0.19 *$ & - & - & - \\
\hline Depersonalisation & 1.61 & 1.47 & 0.85 & 0.85 & $0.16 *$ & 0.14 & $0.57 * *$ & - & - \\
\hline Task performance & 3.64 & 0.85 & 0.89 & 0.89 & -0.03 & 0.12 & $-0.24 * *$ & $-0.35 * *$ & - \\
\hline Counterproductive work behaviour & 1.97 & 0.70 & 0.78 & 0.78 & 0.03 & 0.06 & $0.27 * *$ & $0.34 * *$ & $-0.35 * *$ \\
\hline
\end{tabular}

$M$, mean; SD, standard deviation; $\alpha$, Cronbach's alpha; $p$, composite reliability.

$* *, p \leq 0.001 ; *, p<0.05$.

TABLE 4: Competing structural models.

\begin{tabular}{|c|c|c|c|c|c|c|c|c|c|}
\hline Models & $\chi^{2}$ & $d f$ & $p$ & CFI & TLI & SRMR & $\begin{array}{c}\text { RMSEA } \\
{[90 \% \mathrm{Cl}]}\end{array}$ & AIC & BIC \\
\hline Model 1 & $488.40 *$ & 282 & 0.00 & 0.94 & 0.93 & 0.06 & $\begin{array}{c}0.05 \\
{[0.04,0.06]}\end{array}$ & 21727.46 & 22078.05 \\
\hline Model 2 & $545.61 *$ & 283 & 0.00 & 0.92 & 0.91 & 0.06 & $\begin{array}{c}0.06 \\
{[0.05,0.06]}\end{array}$ & 21792.18 & 22139.07 \\
\hline Model 3 & $632.22^{*}$ & 288 & 0.00 & 0.90 & 0.88 & 0.10 & $\begin{array}{c}0.06 * \\
{[0.06,0.07]}\end{array}$ & 21882.11 & 22210.55 \\
\hline
\end{tabular}

$\chi^{2}$, chi-square statistic; $d f$, degree of freedom; $p$, significance; CFI, comparative fit index; TLI, Tucker-Lewis index; SRMR, standardised root means square residual; RMSEA, root mean square error of approximation; $\mathrm{Cl}$, confidence interval; AIC, Akaike information criterion; BIC, Bayes information criterion.

$*, p<0.05$.

values. In Model 1b, model improvement continued with allowing error variances to correlate between CWB 4 ('I talked to colleagues about the negative aspects of my work') and CWB 5 ('I talked to people outside the organisation about the negative aspects of my work'), also between DP 4 ('I have become more cynical about whether my work contributes anything') and DP 5 ('I doubt the significance of my work') in addition to the items deleted in Model 1a. Correlated errors may occur because of an overlap in item content such as CWB 4 and CWB 5 referring to the negative aspects of work and DP 4 and DP 5 which refer to whether a significant contribution is made to a person's work. Model 1b met the minimum required cut-off values.

Table 3 shows descriptive statistics, the reliability coefficients and correlations between work pressure, emotional demands, depersonalisation, task performance and CWB based on Model $1 \mathrm{~b}$. The reliability coefficients range from 0.78 to 0.91 , indicating acceptable reliability. The relationships between most of the variables were statistically and practically significant with either a small, medium or large effect.

According to the results in Table 3, all the significant correlations were in the expected directions. Work pressure correlated significantly positive with emotional demands ( $r=0.39$; medium effect), exhaustion ( $r=0.47$; medium effect) and depersonalisation ( $r=0.16$; small effect). Emotional demands only correlated significantly with exhaustion $(r=0.19$; small effect). Exhaustion correlated significantly positive with depersonalisation $(r=0.57$; large effect), whereas both exhaustion and depersonalisation correlated with CWB ( $r=0.27$; small effect and $r=0.34$; medium effect, respectively), but negatively with task performance ( $r=-0.24$; small and $r=-0.35$ medium effect, respectively). Neither work pressure nor emotional demands correlated significantly with task performance $(r=-0.03$ and $r=0.12)$ or CWB $(r=0.03$ and $r=0.06)$. This means that there could potentially be mediators involved (i.e. exhaustion and depersonalisation). Emotional demands also did not correlate significantly with depersonalisation $(r=0.14)$.

\section{Testing structural models}

The measurement model formed the basis for the structural models. Three competing structural models were tested. Model 1 (also known as the direct and indirect pathways model) was the hypothesised model with direct and indirect paths between all variables. Model 2 (also known as the direct pathway model) contained only direct pathways from the independent variables (work pressure, emotional demands and exhaustion) to the dependent variables (task performance and CWB). Model 3 (also known as the indirect pathway model) did not contain paths from the work demands variables to the independent variables. Model 1 showed acceptable fit to the data with: $\chi^{2}=488.40, d f=282$, $\mathrm{CFI}=0.94, \mathrm{TLI}=0.93$ and $\mathrm{RMSEA}=0.05(0.04,0.06)$. Model 1 's fit was slightly better than Models 2 and 3 with higher CFI and TLI values, a non-significant RMSEA value as well as lower AIC and BIC values.

Figure 1 shows the standardised path coefficients for the best fitting structural model, which were subsequently used to test indirect effects.

Only four of the regression paths were significant. Hypothesis 1 aimed to determine whether ( $\mathrm{H} 1 \mathrm{a})$ a negative relationship between work pressure and task performance exists and whether $(\mathrm{H} 1 \mathrm{~b})$ a positive relationship between work pressure and CWB exists. Hypotheses $1 \mathrm{a}(\beta=-0.01, p=0.96)$ and $1 \mathrm{~b}$ $(\beta=-0.10, p=0.28)$ were both rejected. Hypothesis 2 aimed to determine whether there is a $(\mathrm{H} 2 \mathrm{a})$ negative relationship between emotional demands and task performance and $(\mathrm{H} 2 \mathrm{~b})$ a positive relationship between emotional demands and CWB. Emotional demands were found to have a positive (not negative) significant relationship with task performance $(\beta=0.18, p<0.05)$; the hypothesis was therefore rejected. In 




FIGURE 1: Structural model of demands, ill-being and performance (dashed lines indicate non-significant regression paths).

relation to Hypothesis $2 b$, emotional demands and CWB did not have a significant positive relationship; therefore, the hypothesis was rejected $(\beta=0.03, p<0.001)$. Hypothesis 3 aimed to determine whether there is a positive relationship between work pressure and ( $\mathrm{H} 3 \mathrm{a})$ exhaustion and $(\mathrm{H} 3 \mathrm{~b})$ depersonalisation. Hypothesis 3a confirmed that there was a significant positive relationship between pressure and exhaustion ( $\beta=0.47, p<0.001)$; thus, the hypothesis was accepted. With reference to Hypothesis $3 b$, the positive relationship between pressure and depersonalisation was not significant $(\beta=0.13, p=0.10)$, and the hypothesis was rejected.

Hypothesis 4 aimed to determine whether there is a positive relationship between emotional demands and (H4a) exhaustion and ( $\mathrm{H} 4 \mathrm{~b})$ depersonalisation. Hypothesis $4 \mathrm{a}$, the relationship between emotional demands and exhaustion, was not significant $(\beta=0.00, p=0.96)$, and the hypothesis was rejected. H4b was also rejected because of a non-significant $(\beta=0.09, p=0.27)$ relationship between emotional demands and depersonalisation. Hypothesis 5 aimed to determine whether there was (H5a) a negative relationship between exhaustion and task performance and $(\mathrm{H} 5 \mathrm{~b})$ a positive relationship between exhaustion and counterproductive work performance. Hypothesis 5a showed a negative relationship between exhaustion and task performance; however, it was not significant ( $\beta=-0.09, p=0.34)$, thus, rejecting the hypothesis.
Hypothesis $5 \mathrm{~b}$ was not accepted, as the relationship was not significant $(\beta=0.16, p=0.16)$. Hypothesis 6 was to determine if there is (H6a) a negative relationship between depersonalisation and task performance and (H6b) a positive relationship between depersonalisation and CWB. Hypothesis 6a was found to have a significant negative relationship between depersonalisation and task performance $(\beta=-0.33, p<0.001)$; therefore, it was accepted. Additionally, Hypothesis $6 \mathrm{~b}$ specified a positive significant $(\beta=-0.27, p<0.001)$ relationship between depersonalisation and CWB.

\section{Indirect effects of work pressure on exhaustion and depersonalisation}

Bootstrapping, with bias-corrected CIs, was used to generate estimations of possible indirect effects. The bias-corrected CIs were set at $95 \%$ for all indirect effects. The lower and upper percentiles served as a limit in that if zero was not contained within these limits, the indirect effects are confirmed (Hayes, 2017). Tables 5 and 6 indicate the lower and upper CIs, as well as the estimates and standard errors of the indirect effects.

As indicated in Tables 5 and 6, none of the indirect effects was significant. The results are supported by the CIs containing zero for both. Therefore, Hypothesis 7, which states that work pressure and emotional demands indirectly affected task performance through ( $\mathrm{H} 7 \mathrm{a})$ exhaustion and $(\mathrm{H} 7 \mathrm{~b})$ 
TABLE 5: Indirect effect of work pressure on task performance and counterproductive work behaviour.

\begin{tabular}{lccccccc}
\hline Variable & \multicolumn{3}{c}{ Exhaustion } & & \multicolumn{3}{c}{ Depersonalisation } \\
\cline { 2 - 4 } \cline { 6 - 8 } & Est. & SE & $\mathbf{9 5 \%} \mathbf{~ C l}$ & & Est. & SE & $\mathbf{9 5 \% ~ C l}$ \\
\hline Task performance & -0.04 & 0.05 & {$[-0.13,0.05]$} & & -0.04 & 0.03 & {$[-0.11,0.00]$} \\
$\begin{array}{l}\text { Counterproductive } \\
\text { work behaviour }\end{array}$ & 0.07 & 0.05 & {$[-0.02,0.19]$} & & 0.03 & 0.03 & {$[0.00,0.11]$} \\
\hline
\end{tabular}

Est., estimate; $\mathrm{SE}$, standard error; $\mathrm{Cl}$, confidence interval.

TABLE 6: Indirect effect of emotional demands on task performance and counterproductive work behaviour.

\begin{tabular}{lccccccc}
\hline \multirow{2}{*}{ Variable } & \multicolumn{3}{c}{ Exhaustion } & & \multicolumn{3}{c}{ Depersonalisation } \\
\cline { 2 - 4 } \cline { 6 - 8 } & Est. & SE & $\mathbf{9 5 \%} \mathbf{~ C l}$ & & Est. & SE & $\mathbf{9 5 \% ~ C l}$ \\
\hline Task performance & 0.00 & 0.01 & {$[-0.02,0.02]$} & & -0.02 & 0.03 & {$[-0.09,0.02]$} \\
$\begin{array}{l}\text { Counterproductive } \\
\text { work behaviour }\end{array}$ & 0.00 & 0.01 & {$[-0.02,0.03]$} & & 0.02 & 0.02 & {$[-0.01,0.08]$} \\
\hline
\end{tabular}

Est., estimate; $\mathrm{SE}$, standard error; $\mathrm{Cl}$, confidence interval.

depersonalisation, was rejected. Hypothesis 8, stating that work pressure $(\mathrm{H} 8 \mathrm{a})$ and emotional demands $(\mathrm{H} 8 \mathrm{~b})$ indirectly affect CWB through exhaustion, was also rejected.

\section{Discussion}

The general aim of this research was to investigate the relationships between work pressure, emotional demands, exhaustion, depersonalisation, task performance and CWB among a sample of IT professionals within South Africa. More specifically, the current study investigated the indirect relationship between work pressure, emotional demands and individual work performance through exhaustion and depersonalisation. This was done to provide an understanding of the role exhaustion and depersonalisation play in explaining the impact of work pressure and emotional demands on individual work performance. It is essential, in today's digital era and IT expansion, for IT professionals to perform optimally as businesses are reliant on IT professionals to ensure optimal organisational functioning.

The aim of the first and second sets of hypotheses entailed investigating the relationship between work pressure, emotional demands, task performance and CWB. Results indicated that work pressure had no direct significant relationship with either task performance or CWB. Emotional demands also had no direct significant relationship with CWB, but surprisingly it was positively associated with task performance. So, when IT professionals experienced emotional demands, they performed their core tasks better. Although these findings (except for the relationship between emotional demands and CWB) contradict mainstream findings (Cafasso, 2018; Plaatjies \& Mitrovic, 2014), it is not surprising if one considers the finer nuances of the JD-R theory. The JD-R theory postulates (1) that job and/or personal resources may buffer the negative impact of job demands (Bakker \& Demerouti, 2017) and (2) that job demands can be divided into challenges or hindrances (LePine, Podsakoff, \& LePine, 2005). Hence all job demands are not equal (Li et al., 2019; Van den Broeck et al., 2010).

Although not measured in the current study, personal resources such as self-efficacy or optimism help employees to performance despite the demands being placed on them (Bakker \& Demerouti, 2017). For many years, the IT field has been a high-pressure environment as technology has been advancing at a rapid rate. Therefore, it has become a norm to work under pressure within the IT field (Grier, 2018). The more one works under pressure, the better one becomes at it (Grier, 2018). The personal resources that IT professionals develop may be a buffer protecting them from the adverse performance effects of the demand. Similarly, because of the nature of their job, it could be that IT professionals have developed coping mechanisms (that becomes personal resources) to deal with emotional demands. Such mechanisms may include increased effort to avoid customer complaints which could also explain the positive relationship between this emotional demands and task performance.

Challenge demands are those job demands that not only require an effort but also present growth and development opportunities (Podsakoff, LePine, \& LePine, 2007). Examples include, among others, workload and pressure (LePine et al., 2005). Meta-analytic studies confirmed the positive outcomes of challenge demands (Lesener et al., 2019; Podsakoff et al., 2007). On the other hand, hindrance demands are those job demands that involve excessive or unwanted constraints that prevent the employee from achieving their goals (Cavanaugh, Boswell, Roehling, \& Boudreau, 2000). Meta-analytic results confirm the adverse outcomes associated with hindrance demands (Crawford, LePine, \& Rich, 2010). More recent studies also advocate for a distinction between low challenge and high challenge demands because they have a differential impact on well-being (see Li et al., 2019). Using this line of reasoning, it may be that the sample from this study does not perceive work pressure as a high hindering demand, and as such, it does not hamper task performance. Neither does it trigger CWB. In addition, IT professionals under pressure may not exercise $\mathrm{CWB}$, because when they are under pressure, they may not have the time, effort or energy to purposefully oppose the goals and aims of their employer (Yang \& Diefendorff, 2009).

It is also plausible then that the current sample perceives emotional demands as a challenging demand. Researchers (Bakker \& Sanz-Vergel, 2013) have previously categorised emotional demands as a challenge demand. This will also support the non-significant association with CWB, which is in line with previous research (see Chen et al., 2017). This means that IT professionals do not allow emotional demands to influence them to the extent that they want to harm the organisation's goals and that they will still uphold a certain work ethic regardless of the emotional turmoil. However, more research is needed to provide conclusive evidence, and this research should also measure the moderation effect of appraisals on the demand-performance relationship (see Li et al., 2019).

The third and fourth sets of hypotheses aimed to determine if a relationship exists between work pressure, emotional demands, exhaustion and depersonalisation. Results 
indicated that work pressure had a positive relationship with exhaustion, but not with depersonalisation. This indicates that work pressure is harmful to the extent that it exhausts IT professionals, but it does not translate into negative (i.e. cynical) attitudes. Previous research also found that work pressure had a more substantial effect on exhaustion than on depersonalisation (Brouwers, Tomic, \& Boluijt, 2011). As the results depict, it seems that IT professionals who have increased work pressure (because of high demands) become more exhausted as more energy is needed to deal with their workload. Again, using the high versus low hindering demand line of reasoning, it may be that work pressure is only a low hindering demand, which may result in exhaustion but not depersonalisation (or CWB as indicated earlier). Results indicated that emotional demands had no significant directrelationship witheitherexhaustionordepersonalisation. Again, using the challenge versus hindrance argument, emotional demands may not be perceived as a hindrance. Alternatively, IT professionals detach themselves from interpersonal issues, as a coping mechanism, with no negative well-being consequences. Previous studies have indicated that psychological detachment decreases wellbeing complaints (Sonnentag, Binnewies, \& Mojza, 2010; Sonnentag \& Fritz, 2007).

The aim of the fifth and six sets of objectives was to determine if a relationship exists between exhaustion, depersonalisation, task performance and CWB. Results indicated that there was no significant relationship between exhaustion, task performance and CWB. Although work pressure increases exhaustion, exhaustion holds no negative consequences for performance. Once again, a job or personal resource may buffer the outcomes of exhaustion (Bakker \& Demerouti, 2017). The non-significant relationship between exhaustion and CWB shows that IT professionals, who experience exhaustion, do not have the energy to work against the organisation's 'current' goals. Counterproductive work performance is an individual's conscious decision to work counterproductively; however, when an IT professional is exhausted, he/she may make mistakes rather than be guilty of sabotage.

The results showed that there was a significant negative relationship between depersonalisation, task performance and CWB. Because of the nature of the work of IT professionals, sometimes performing repetitive tasks and having a monotonous type of job when it comes to some of their primary functions, the result of this is that IT professionals start depersonalising and detaching themselves from their actual work (Doyle, 2019). This leads to not only more mediocre performance of core tasks but also engagement in CWB that harms the organisation. Previous studies also showed that depersonalisation had a significantly negative relationship with task performance (Lee et al., 2018; Studebaker, 2017) and a significantly positive relationship with CWB (Bolton et al., 2012; Gorji, 2011).

The aim of the seventh and eight sets of hypotheses was to determine whether work pressure and emotional demands indirectly affect task performance and CWB through exhaustion and depersonalisation. The results indicated that work pressure and emotional demands had no significant indirect effect on task performance. Even though work pressure leads to exhaustion, it is not detrimental enough, or alternatively something (i.e.job or personal resource)buffers the consequential negative impact of exhaustion on performance. On the other hand, depersonalisation is detrimental to task performance. The detachment behaviour and negative attitudes towards their work and more specifically towards their task show that IT professionals detach themselves from their tasks, which in turn influences their task performance. However, depersonalisation is not caused by work pressure but may be ascribed to other demands (e.g. cognitive load or role ambiguity) not measured in the current study. The results indicated that work pressure and emotional demands had no significant indirect effect on CWB through either exhaustion or depersonalisation. As explained earlier, neither work pressure nor emotional demands associated with depersonalisation; yet depersonalisation showed negative consequences for performance.

\section{Implications for management}

Managers need to understand what influences IT professionals' work performance and well-being (Taris \& Schaufeli, 2015). Even though work pressure is not detrimental to an IT professional's performance, it is detrimental to their well-being. Work pressure can be motivating, but only the perfect type of pressure (i.e. low hindering) can help a team remain focussed and productive, without being exhausted (Grier, 2018). To find the 'perfect' type of pressure, managers could distribute workloads evenly in their teams and work with the IT professionals to determine realistic deadlines and timeframes to complete the tasks. Managers could also provide IT professionals with an opportunity to perform their tasks outside regular operating hours (introducing flexitime) within the negotiated timeframes.

Additionally, managers can introduce effort recovery strategies (Els, Mostert, \& De Beer, 2015). Effort-recovery strategies during work hours include actions such as encouraging lunch breaks away from their desks and providing IT professionals with the freedom to schedule their day-to-day tasks in line with the outcomes for that day. Managers can also encourage IT professionals to apply effort recovery strategies after work, such as playing games, participating in voluntary work and physical activities, and improving their sleep quality.

Similarly, the right type (i.e. high challenging) of emotional demands can be motivating. Managers can, for example, encourage positive competition between peers by rewarding IT professionals for successfully managing a difficult client, based on the time taken to resolve the task and calm the client. This also enhances a learning culture as the IT professional who does this the quickest and most efficiently can teach other colleagues how to go about it. However, managers need to assist IT professionals in optimising their coping mechanisms in dealing with emotional demands. This can be done by (1) providing IT 
professionals with a standard operating procedure (SOP) and (2) training them. An SOP, together with training, may help them to deal with demanding clients and may prevent them from engaging in rude behaviours when dealing with clients. Additionally, managers can arrange a mindfulness workshop that aids IT professionals in understanding how they perceive a work environment, gaining knowledge about themselves and how to be mindful of their reaction to situations, especially when dealing with clients.

Additionally, management and IT professionals should fully understand the signs and symptoms of a person experiencing depersonalisation. This could be achieved through a workshop that provides them with tools on how to identify and deal with depersonalisation. Examples of these tools could be to teach them not to overact and thus enhance feelings of detachment; to promote an exciting work environment so that tedious, monotonous tasks are completed easily; and to attempt to involve and engage them in work conversations. Lastly, management and IT professionals should attend external workshops that deal with the signs of depersonalisation and exhaustion. Such workshops enable all to notice when colleagues are experiencing feelings of detachment, cynicism or exhaustion.

\section{Limitations and recommendations for future research}

The study had several methodological limitations that should be taken into consideration when interpreting the current results. Firstly, the study was cross-sectional. Causal interpretations could not be made about the relationships between constructs (Spector, 2019) or reciprocal relationships between the variables (Lesener et al., 2019). In future, a longitudinal design should be employed to determine (1) whether work pressure and emotional demands cause individual work performance and/or vice versa and (2) to confirm that the non-significant results were not because of measurement artefacts. Secondly, the questionnaires were self-report measures, and this often causes common method variance. Although none of the correlations in the current study were high, self-report surveys may inflate correlations between predictors and outcomes (Spector, Rosen, Richardson, Williams, \& Johson, 2019). In future, researchers could use multi-source data from managers and employees. Thirdly, convenience sampling was used, which may influence the generalisability of the findings. More robust sampling methods are recommended for future research. Last, organisational life and well-being should be modelled at the organisational, team and individual levels and not only at the individual level. When utilising a multilevel approach, it can shed light on how these processes play out on different levels (Bakker \& Demerouti, 2018). Researchers could also include appraisal measures that can account for the type (i.e. low/high challenge vs hindrance) of job demands.

The first theoretical limitation of the study was that only two job demands were included. Several other demands (e.g. cognitive demands, role conflict and hassles at work) can also be investigated in future research. The second theoretical limitation is that the JD-R theory does include not only job demands but also the role that job resources play in buffering the consequences of job demands. More specifically, among IT professionals, it is vital to study job resources as IT professionals may value growth and opportunities that buffer the demands. The last theoretical limitation is that personal resources (as an element of the JD-R theory) were not included in this study. Future researchers should include personal resources in their study as they directly impact wellbeing; personal resources moderate the relation between job characteristics and well-being or influence the perception of job characteristics (Van den Broeck et al., 2010).

\section{Conclusion}

Despite limitations, results indicated that emotional demands and depersonalisation impacted the task performance of IT professionals positively and negatively, respectively. Work pressure positively impacted their exhaustion, whereas emotional demands positively impacted their task performance. Depersonalisation had implications for IT professionals' task performance and CWB, albeit in different directions. This study contributes to the literature by highlighting the importance of distinguishing for whom job demands are detrimental. As the results show, not all job demands are equal in terms of their impact on well-being and performance.

\section{Acknowledgements}

We thank Prof. Leon de Beer for the critical reading of the manuscript.

\section{Competing interests}

The authors have declared that no competing interest exists.

\section{Authors' contributions}

J.T. conceptualised and wrote the manuscript, L.v.d.V. conducted the data analysis and supervised J.T.

\section{Funding information}

This research received no specific grant from any funding agency in the public, commercial or not-for-profit sectors.

\section{Data availability statement}

Data sharing will be done in line with ethics requirements. The data and syntaxes are the intellectual property of the North-West and will be provided upon reasonable requests. Contact author for more information.

\section{Disclaimer}

The views and opinions expressed in this article are those of the authors and do not necessarily reflect the official policy or position of any affiliated agency of the authors. 


\section{References}

Adams, R. P. (2018). Model selection and cross validation. Retrieved from https:// www.cs.princeton.edu/courses/archive/fall18/cos324/files/model-selection.pdf

Aguinis, H. (2013). Performance management. Upper Saddle River, NJ: Pearson Prentice Hall.

Ahuja, V., \& Rathore, S. (2018). Multidisciplinary perspectives on human capital and information technology. Pennsylvania, PA: IGI Global Publishers.

Anderson, J., \& Rainie, L. (2018). Concerns about the future of people's well-being Retrieved from https://www.pewinternet.org/2018/04/17/concerns-about-thefuture-of-peoples-well-being/

Bakker, (2014). The Job Demands-Resources Questionnaire [Technical Manual]. Rotterdam: Rotterdam University.

Bakker, A.B., \& Demerouti, E. (2014). Job demands-resources theory. In C. Cooper \& P. Chen (Eds.), Wellbeing: A complete reference guide (pp. 37-64). Chichester: Wiley-Blackwell.

Bakker, A.B., \& Demerouti, E. (2017). Job demands-resources theory: Taking stock and looking forward. Journal of Occupational Health Psychology, 22(3), 273-285. https://doi.org/10.1037/ocp0000056

Bakker, A.B., \& Demerouti, E. (2018). Multiple levels in job demands-resources theory Implications for employee well-being and performance. Retrieved from https:// nobascholar.com/chapters/36/download.pdf

Bakker, A.B., Demerouti, E., Taris, T.W., Schaufeli, W.B., \& Schreurs, P.J.G. (2003) A multi group analysis of the job demands-resources model in four home care organizations. International Journal of Stress Management, 10, 16-38. https:// doi.org/10.1037/1072-5245.10.1.16

Bakker, A.B., \& Sanz-Vergel, A.I. (2013). Weekly work engagement and flourishing: The role of hindrance and challenge job demands. Journal of Vocational Behavior, 83(3), 397-409. https://doi.org/10.1016/j.jvb.2013.06.008

Bakker, A.B., Schaufeli, W.B., Sixma, H., Bosveld, W., \& Van Dierendonck, D. (2000) Patient demands, lack of reciprocity, and burnout: A five-year longitudinal study among general practitioners. Journal of Organisational Behaviour, 21, 1099-1379. https://doi.org/10.1002/(SICI)1099-1379(200006)21:43.0.CO;2-\#

Bang, H., \& Reio, T.G. (2017). Examining the role of cynicism in the relationships between burnout and employee behaviour. Journal of Work and Organisation Psychology, 33, 217-227. https://doi.org/10.1016/j.rpto.2017.07.0021576-5962/

Barker, S. (2016). Psychology for nursing and healthcare professionals: Developing compassionate care. New York, NY: Springer Publishers.

Bolton, L.R., Harvey, R.D., Grawitch, M.J., \& Barber, L.K. (2012). Counterproductive work behaviours in response to emotional exhaustion: A moderated mediational approach. Stress Health, 3, 222-233. https://doi.org/10.1002/smi.1425

Brooks, N.G., Greer, T.H., \& Morris, S.A. (2018). Information systems security job advertisement analysis: Skills review and implications for information systems curriculum. Journal of Education for Business, 93(5), 213-221. https://doi.org/10. 1080/08832323.2018.1446893

Brouwers, A., Tomic, W., \& Boluijt, H. (2011). Job demands, job control, social support and self-efficacy beliefs as determinants of burnout among physical education teachers. Europe's Journal of Psychology, 7(1), 1-23. https://doi.org/10.5964/ ejop.v7i1.103

Cafasso, J. (2018). Emotional exhaustion: What it is and how to fix it. Retrieved from https://www.healthline.com/health/emotional-exhaustion

Campbell, J.P. (1990). Modeling the performance prediction problem in industrial and organizational psychology. In M.D. Dunnette \& L.M. Hough (Eds.), Handbook of industrial and organizational psychology (pp. 687-732). Palo Alto, CA: Consulting Psychologists Press.

Campbell, A. (2016). Overworked employees? 15 Signs you may be pushing workers too hard. Retrieved from https://www.americanexpress.com/us/small-business/ openforum/articles/overworked-employees-15-signs-may-pushing-workershard/

Cavanaugh, M.A., Boswell, W.R., Roehling, M.V., \& Boudreau, J.W. (2000). An empirical investigation of self-reported work stress among US managers. Journal of Applied Psychology, 85(1), 65-74. https://doi.org/10.1037//0021-9010.85.1.65

Ceschi, A., Sartori, R., Dickert, S., \& Costantini, A. (2016). Grit or honesty-humility? New insights into the moderating role of personality between the health impairment process and counterproductive work behavior. Frontiers in Psychology, 7, 1799. https://doi.org/10.3389/fpsyg.2016.01799

Chen, Y., Li, S., Xia, Q., \& He, C. (2017). The relationship between job demands and employees' counterproductive work behaviors: The mediating effect of psychological detachment and job anxiety. Frontiers in Psychology, 8, 1890 https://doi.org/10.3389/fpsyg.2017.01890

Cohen, J. (1992). Statistical power analysis. Current Directions in Psychological Science, 1, 98-101. https://doi.org/10.1111/1467-8721.ep10768783

Conradie, W.J., \& De Klerk, J.J. (2019). To flex or not to flex? Flexible work arrangements amongst software developers in an emerging economy. SA Journal of Human Resource Management/SA Tydskrif vir Menslikehulpbronbestuur, 17(0), a1175. https://doi.org/10.4102/sajhrm.v17i0.1175

Crawford, E., Lepine, J.A., \& Rich, B.L. (2010). Linking job demands and resources to employee engagement and burnout: A theoretical extension and meta-analytic test. Journal of Applied Psychology, 95(5), 834-848. https://doi.org/10.1037/ a0019364

Deal, J.J. (2013). Work life balance: Welcome to the 72-hour work week. Retrieved from https://hbr.org/2013/09/welcome-to-the-72-hour-work-we
De Beer, L.T., \& Bianchi, R. (2019). Confirmatory factor analysis of the Maslach Burnout Inventory: A Bayesian structural equation modelling approach. European Journal of Psychological Assessment, 35(2), 217-224. https://doi.org/10.1027/1015of Psychological

Demerouti, E., Bakker, A.B., Nachreiner, F., \& Schaufeli, W.B. (2001). The job demandsresources model of burnout. Journal of Applied Psychology, 86(3), 449-512. https://doi.org/10.1037/0021-9010.86.3.499

Diedericks, E., \& Rothmann, S. (2014). Flourishing of information technology professionals: Effects on individual and organisational outcomes. South African Journal of Business Management, 45(1), 27-40.

Doyle, A. (2019). Information technology (IT) skills list and examples. Retrieved from https://www.thebalancecareers.com/list-of-information-technology-itskills-2062410

Els, C., Mostert, K., \& De Beer, L.T. (2015). Job characteristics, burnout and the relationship with recovery experiences. SA Journal of Industrial Psychology, 41(1) Art. \#1196, 13 pages. https://doi.org/10.4102/sajip.v41i1.1196

Gauche, C., De Beer, L.T., \& Brink, L. (2017). Managing employee well-being: A qualitative study exploring job and personal resources of at-risk employees. South African Journal of Human Resource Management, 15(0), Art. \#957, 13 pages. https://doi.org/10.4102/sajhrm.v15i0.957

Gorji, M. (2011). The effect of job burnout dimension on employees' performance. International Journal of Social Science and Humanity, 1(4), 243-246. https://doi. org/10.7763/IJSSH.2011.V1.43

Grier, S. (2018). How to work under pressure. Retrieved from http://www. itmanagersinbox.com/1549/how-to-work-under-pressure/

Hayes, A.F. (2017). Introduction to meditation, moderation, and conditional process analysis (2nd edn.). New York, NY: Guilford Press.

Holly, K.Z. (2018). The most important tech trend of 2018 won't be a technology. Retrieved from https://www.forbes.com/sites/krisztinaholly/2018/01/26/techtrends-2018-amazon/\#1c291c784054

Hsu, H. C. (2019). Age differences in work stress, exhaustion, well-being, and related factors from an ecological perspective. International Journal of Environmental factors from an ecological perspective. International Journal of Environmental
Research and Public Health, 16(1), 1-50. https://doi.org/10.3390/ijerph16010050

Hu, L., \& Bentler, P.M. (1999). Cut-off criteria for fit indexes in covariance structure analysis: Conventional criteria versus new alternatives. Structural Equation Modeling: A Multidisciplinary Journal, 6(1), 1-27. https://doi.org/10.1080/ 10705519909540118

IBM Corporation. (2016). IBM SPSS statistics for Windows, version 25.0. Armonk, NY: IBM Corporation.

Kar, S., \& Suar, D. (2014). Role of burnout in the relationship between job demands and job outcomes among Indian nurses. VIKALPA, 39(4), 23-38. https://doi. org/10.1177/0256090920140403

Kline, R.B. (2016). Principles and practice of structural equation modeling (4th edn.). New York, NY: The Guilford Press.

Koong, K.S., Liu, L.C., \& Lui, X. (2015). A study of the demand for information technology professionals in selected internet job portals. Journal of Information technology professionals in selected internet job portals. Journal of Information publication/268354704 A Study of the Demand for Information publication $/ 268354704$ _A_Study_of_the_Demand_f
Technology_Professionals_in_Selected_Internet_Job_Portals

Koopmans, L. (2015). Individual Work Performance Questionnaire [Instruction Manual]. Rotterdam: TNO Innovation for Life - VU University Medical Center.

Koopmans, L., Bernaards, C., Hildebrandt, V., Schaufeli, W.B., De Vet, H.C.W., \& Van der Beek, A.J. (2011). Conceptual frameworks of individual work performance: A systematic review. American College of Occupational and Environmental Medicine, 53(8), 556-866. https://doi.org/10.1097/JOM.0b013e318226a763

Lang, J., Thomas, J.L., Bliese, P.D., \& Adler, A.B. (2007). Job demands and job performance: The mediating effect of psychological and physical strain and the moderating effect of role clarity. Journal of Occupational Health Psychology, 12(2), 24-116. https://doi.org/10.1037/1076-8998.12.2.116

Lee, J., Ok, C.M., Lee, S., \& Lee, C. (2018). Relationship between emotional labor and customer orientation among airline service employees: Mediating role of depersonalization. Journal of Travel Research, 57(3), 324-341. https://doi. org/10.1177/0047287517696

LePine, J.A., Podsakoff, N.P., \& LePine, M.A. (2005). A meta-analytic test of the challenge stressor-hindrance stressor framework: An explanation for inconsistent relationships among stressors and performance. Academy of Management Journal, 48(5), 764-775. https://doi.org/10.5465/amj.2005.18803921

Lesener, T., Gusy, B., \& Wolter, C. (2019). The job demands-resources model: A metaanalytic review of longitudinal studies. Work \& Stress, 33(1), 76-103. https://doi. org/10.1080/02678373.2018.1529065

Li, P., Taris, T.W., \& Peeters, M.C.W. (2019). Challenge and hindrance appraisals of job demands: One man's meat, another man's poison? Anxiety, Stress \& Coping, 33(1), 31-46. https://doi.org/10.1080/10615806.2019.1673133

Marr, B. (2018). The 4th industrial revolution is here - Are you ready? Retrieved from https://www.forbes.com/sites/bernardmarr/2018/08/13/the-4th-industrialrevolution-is-here-are-you-ready/\#10211c6f628b

Maslach, C., \& Jackson, S.E. (1986). Maslach burnout inventory (2nd edn.). Palo Alto, CA: Consulting Psychologists Press.

Maslach, C., \& Leiter, M.P. (2016). Understanding the burnout experience: Recent research and its implications for psychiatry. PubMed, 15(2), 11-103. https://doi. org/10.1002/wps.20311

Murphy, J. (2018). Four essential skills for workplace success: In the 21st century digital economy. Retrieved from https://www.forbes.com/sites/
forbescommunicationscouncil/2018/04/27/four-essential-skills-for-workplacesuccess-in-the-21st-century-digital-economy/\#5577afc23fa4 
Muthén, B.O., \& Muthén, L.M. (1998-2018). Mplus (Version 8.2). Computer software. Los Angeles, CA: Muthén \& Muthén.

Naidoo, R. (2018). Role stress and turnover intentions among information technology personnel in South Africa: The role of supervisor support. South African Journal of Human Resource Management, 16(0), Art. \#936, 10 pages. https://doi. org/10.4102/sajhrm.v16i0.936

Nexus Group. (2018, April). The problems that IT departments are struggling with in 2018. Retrieved from https://www.nexusgroup.com/the-problems-that-itdepartments-are-struggling-with-in-2018

Onwezen, M.C., Van Veldhoven, M.J.P.M., \& Biron, M. (2014). The role of psychological flexibility in the demands-exhaustion-performance relationship. European Journal of Work and Organizational Psychology, 23(2), 163-176. https://doi.org/10.1080/ of Work and Organizational
$1359432 X .2012 .742242$

Plaatjies, F., \& Mitrovic, Z. (2014). ICT and skills shortage: South African case study of retaining ICT-skilled professionals. Retrieved from http://proceedings. e-skillsconference.org/2014/e-skills351-369Plaatjies686.pd

Podsakoff, N.P., LePine, J.A., \& LePine, M.A. (2007). Differential challenge stressor hindrance stressor relationships with job attitudes, turnover intentions, turnover, and withdrawal behavior: A meta-analysis. Journal of Applied Psychology, 92(2), 438-454. https://doi.org/10.1037/0021-9010.92.2.438

Raykov, T. (2009). Evaluation of scale reliability for unidimensional measures using Evaluation in Counselling \& Development, 42(3), 223-232. https://doi.org/10.1177/0748175609344096

Rutkowski, A., \& Saunders, C. (2018). Emotional and cognitive overload: The dark side of information technology. London: Routledge.

Schaufeli, W.B. (2017). Applying the job demands-resources model: A 'how to' guide to measuring and tackling work engagement and burnout. Organizational Dynamics, 46(1), 120-132. https://doi.org/10.1016/j.orgdyn.2017.04.008

Schaufeli, W.B., \& Bakker, A. (2004). Job demands, job resources, and their relationship with burnout and engagement: A multi-sample study. Journal of Organizational with burnout and engagement: A multi-sample study. J
Behavior, 25, 293-315. https://doi.org/10.1002/job.248

Schaufeli, W.B., Leiter, M.P., Maslach, C., Jackson, S.E., \& Schwab, R.L. (1996). MB general survey - MBI-GS [Instruments and scoring keys]. Mind Garden.

Schaufeli, W.B., \& Taris, T.W. (2014). A critical review of the job demands-resources model: Implications for improving work and health. Retrieved from https://www. wilmarschaufeli.nl/publications/Schaufeli/411.pdf

Schwab, K. (2016). Fourth industrial revolution - What it means and how to respond Retrieved from https://www.weforum.org/agenda/2016/01/the-fourth-industrialRetrieved from https://www.weforum.org/agend
revolution-what-it-means-and-how-to-respond/

Sonnentag, S., Binnewies, C., \& Mojza, E.J. (2010). Staying well and engaged when demands are high: The role of psychological detachment. Journal of Applied Psychology, 95(5), 965-976. https://doi.org/10.1037/a0020032

Sonnentag, S., \& Fritz, C. (2007). The Recovery Experience Questionnaire Development and validation of a measure for assessing recuperation and unwinding from work. Journal of Occupational Health Psychology, 12(3), 204-221. https://doi.org/10.1037/1076-8998.12.3.204

Spector, P.E. (2019). Do not cross me: Optimizing the use of cross-sectional designs. Journal of Business and Psychology, 34, 125-137. https://doi.org/10.1007/ s10869-018-09613-8

Spector, P.E., Rosen, C.C., Richardson, H.A., Williams, L.J., \& Johnson, R.E. (2019). A new perspective on method variance: A measure-centric approach. Journal of Management, 45(3), 855-880. https://doi.org/10.1177/0149206316687295

Studebaker, K. (2017). The 5 most common problems your company faces. Retrieved from https://www.coordinated.com/blog/5-common-it-problems
Taris, T.W., \& Schaufeli, W.B. (2015). Individual well-being and performance at work. Retrieved from https://www.wilmarschaufeli.nl/publications/Schaufeli/434.pdf

Tomo, A., \& De Simone, S. (2018). Using the job demands-resources approach to assess employee well-being in healthcare. Retrieved from https://journals. sagepub.com/doi/abs/10.1177/0951484818787687

Tourigny, L., Baba, V.V., Han, J., \& Wang, X. (2012). Emotional exhaustion and job performance: The mediating role of organizational commitment. The Internationa Journal of Human Resource Management, 1, 514-532. https://doi.org/10.1080/0 9585192.2012.694109

Ugwu, L.I., Enwereuzor, I.K., Fimber, U.S., \& Ugwu, D.I. (2017). Nurses' burnout and counterproductive work behaviour in a Nigerian sample: The moderating role of emotional intelligence. International Journal of Africa Nursing Sciences, 7(1), 106-113. https://doi.org/10.1016/j.ijans.2017.11.004

Vammen, M.A. (2016). Emotional demands at work, physiological mechanisms, and mental health. Retrieved from https://www.bispebjerghospital.dk/afdelinger-ogklinikker/arbejds-og-miljoemedicinsk-afdeling/forskning/Phd-afhandlinger-ogdisputatser/Documents/2016_PhD_Marianne_A_Vammen.pdf

Van Dyk, J., \& Coetzee, M. (2012). Retention factors in relation to organisational commitment in medical and information technology services. SA Journal of Human Resource Management/SA Tydskrif vir Menslikehulpbronbestuur, 10(2), Art. \#433, 11 pages. http://dx.doi.org/10.4102/sajhrm.v10i2.433

Van den Broeck, A., De Cuyper, N., De Witte, H., \& Vansteenkiste, M. (2010). Not all job demands are equal: Differentiating job hindrances and job challenges in the job demands-resources model. European Journal of Work and Organizational Psychology, 19(6), 735-759. https://doi.org/10.1080/13594320903223839

Van Zyl, L.E., Van Oort, A., Rispens, S., \& Olckers, C. (2019). Work engagement and task performance within a global Dutch ICT-consulting firm: The mediating role of innovative work behaviors. Current Psychology. https://doi.org/10.1007/s12144019-00339-1\&domain=pdf

Vorster, P. (2018). Understanding and combating counterproductive work behaviours. Retrieved from https://www.tei.org.za/index.php/resources/articles/businessethics/7496-understanding-and-combating-counterproductive-work-behaviours

Wallgren, R.G. (2013). Theory Y embedded in theory X: The limited role of autonomy in decreasing perceived stress among IT consultants. International Journal of Human Capital and Information Technology Professionals, 4(4), 1-17. https://doi. org/10.4018/ijhcitp.2013100101

Wang, J., \& Wang, X. (2020). Structural equation modelling (2nd edn.). Chichester: Wiley.

West, S.G., Taylor, A.B., \& Wu, W. (2012). Model fit and model selection in structural equation modeling. In R.H. Hoyle (Ed.), Handbook of structural equation modeling (pp. 209-231). New York, NY: The Guilford Press.

Yang, J., \& Diefendorff, J.M. (2009). The relations of daily counterproductive workplace behavior with emotions, situational antecedents, and personality moderators: A diary study in Hong Kong. Journal of Personnel Psychology, 62(2), 259-295. https://doi.org/10.1111/j.1744-6570.2009.01138.x

Zakaria, M., Abdulatiff, N.K., \& Ali, N. (2014). The role of wellbeing on performance in services sector. Procedia - Social and Behavioral Sciences, 164, 358-365. https:// doi.org/10.1016/j.sbspro.2014.11.088

Zakariah, S.H., Zainal, A., \& Shariff, F.M. (2018). Enhancing the role of innovation towards employee job performance at Malaysian hotels. International Journal of Academic Research in Business and Social Sciences, 8(15), 146-159. https://doi. org/10.6007/IJARBSS/v8-i15/5098 